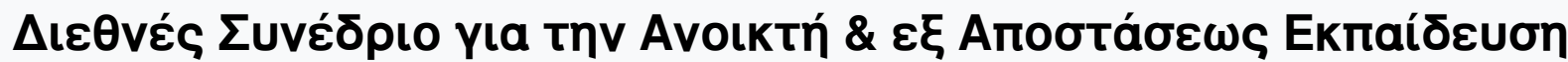

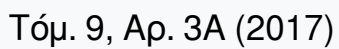

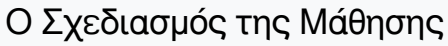

\section{Tónos 3, Mépos A}

\section{Практіка́}

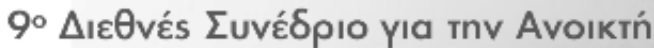

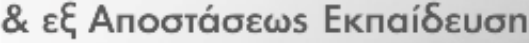

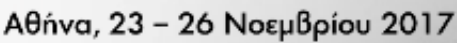

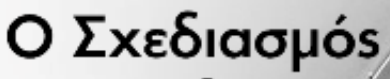 ins MáӨnons}

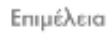

Avióvns Aıvapákns

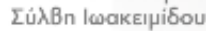

Mapia Niápn

Tké̉n Mavoúoou

Tóvia Xaproqú

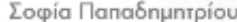

Avva Anoorodibou

ISBN 978-618-82258.8.6

ISBN SET 978-618-82258-5-5

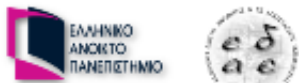

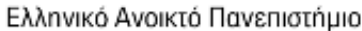

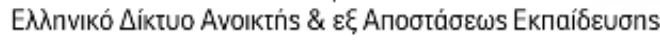

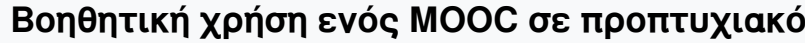
$\mu a ́ \theta \eta \mu a$

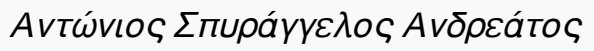

doi: $10.12681 /$ icodl. 1161 


\title{
Using a MOOC in an undergraduate face-to-face course
}

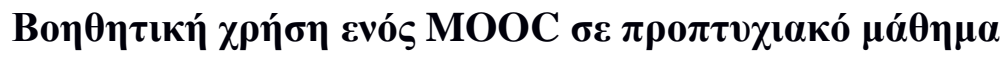

\author{
Antonios Andreatos \\ Div. of Computer Engineering and Information Science \\ Hellenic Air Force Academy \\ Dekeleia Air Force Base \\ Dekeleia, Attica, TGA-1010 \\ GREECE \\ antonios.andreatos@hafa.haf.gr, aandreatos@gmail.com
}

\begin{abstract}
This paper describes the use of a free external MOOC as a supplement to the face-toface syllabus in an undergraduate course about Internet technologies, based on the socalled LAMP stack. Since this was their first contact with MOOCs, student reactions and MOOC acceptance are investigated by qualitative research. Although there was some scepticism among the students in the beginning, finally they liked this new way of learning. Six out of eight students managed to finish the MOOC and presented a certificate, while the other two nearly finished. The students assessed the course and the instructor positively while they were able to easily perceive the material. In case some of them had questions, they would replay the video or search for the answer in Google; it seems that the students did not use the Questions and Answers forum of the MOOC. By the interview time (May 2017), six out of eight students declared that they will attend more MOOCs related to their courses in the future, while three of them had already enrolled, out of which, one had already finished four courses and the other, one course.
\end{abstract}

Key-words: MOOCs, undergraduate course, qualitative research, interviews, Internet technologies, LAMP stack.

\section{Пєрі́ $\eta \psi \eta$}

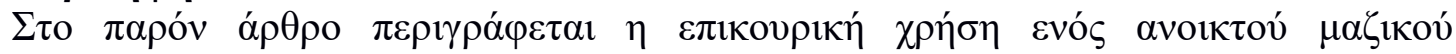

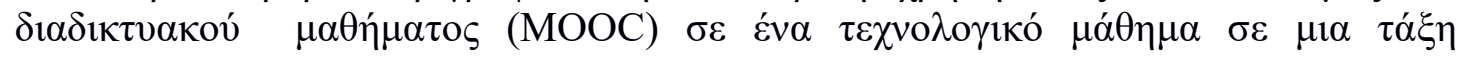

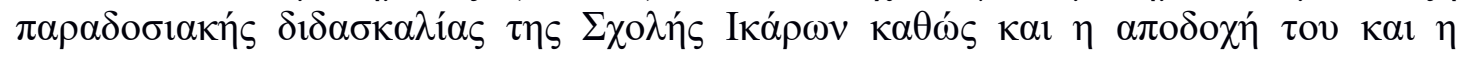

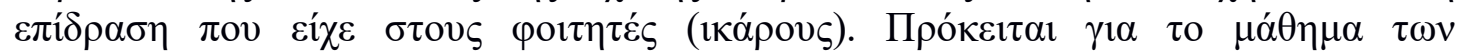

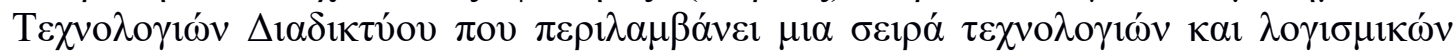

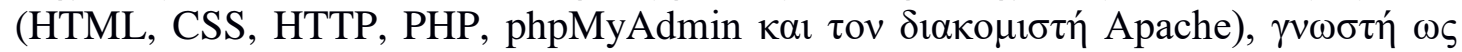

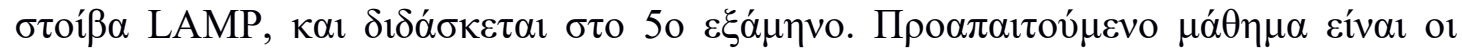

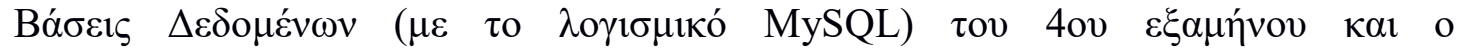

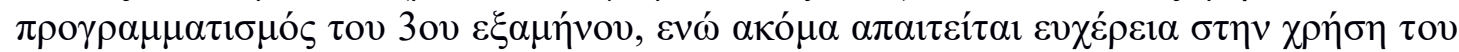

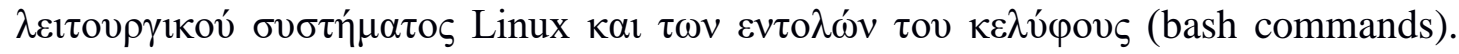

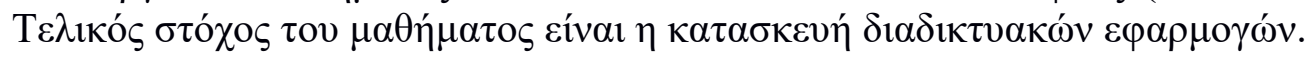

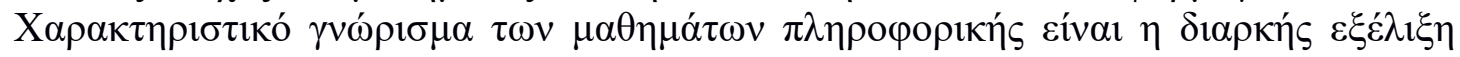

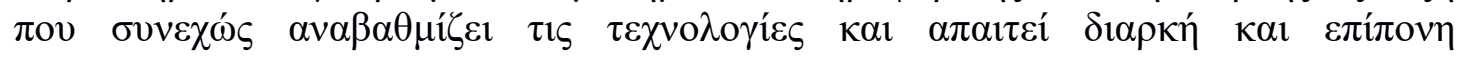

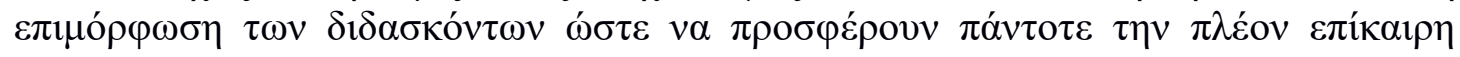

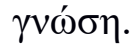




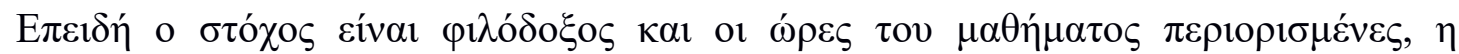

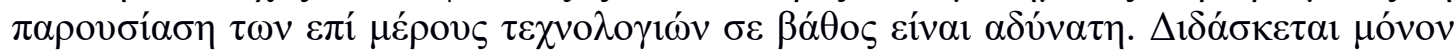

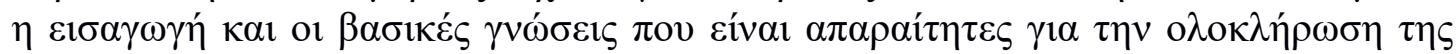

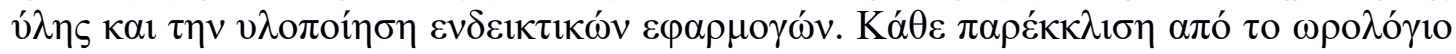

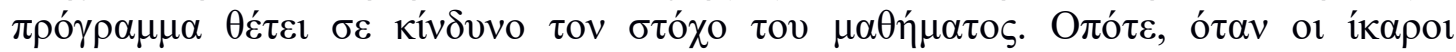

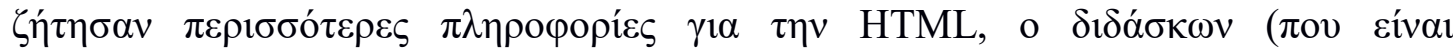

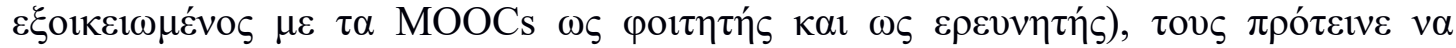

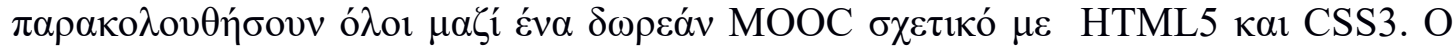

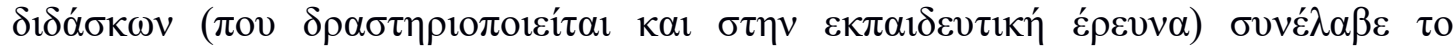

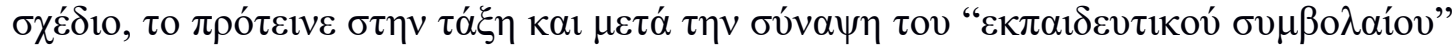

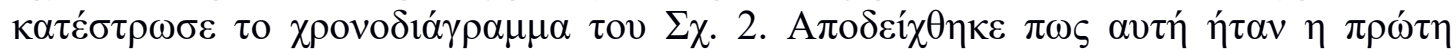

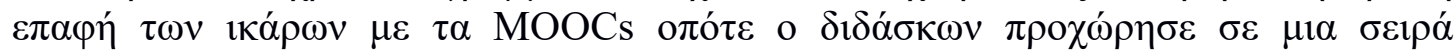

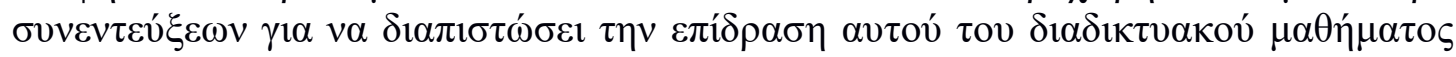

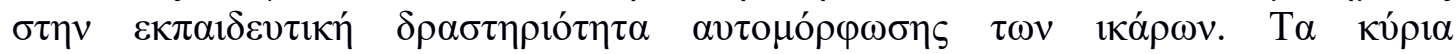

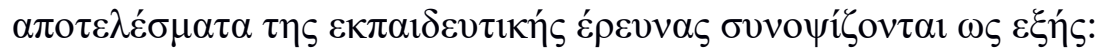

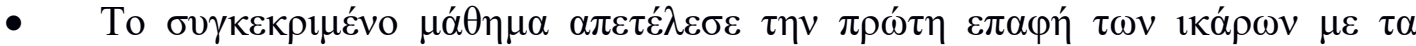

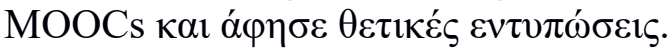

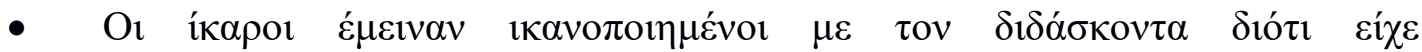

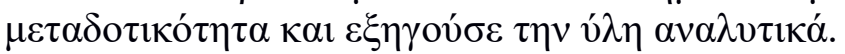

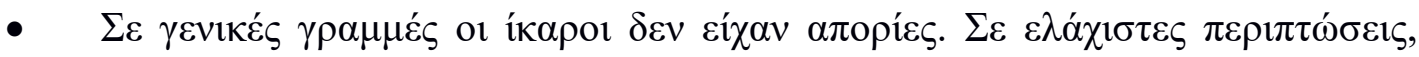

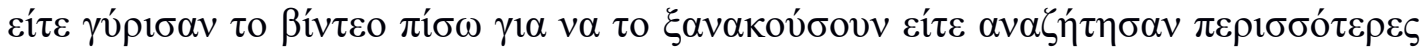

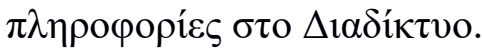

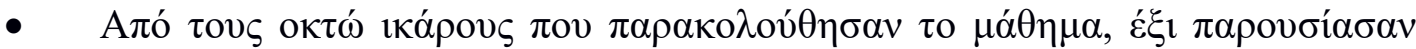

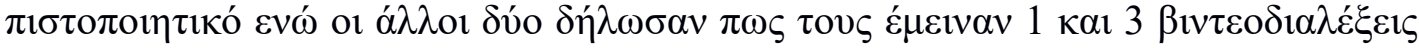
$\alpha v \tau i ́ \sigma \tau o \imath \chi \alpha$.

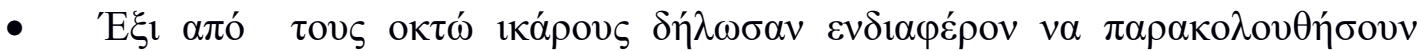

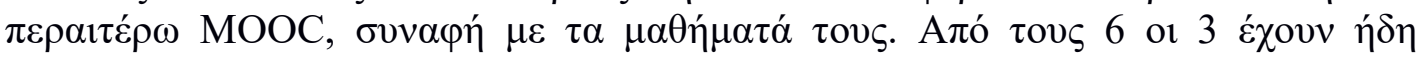

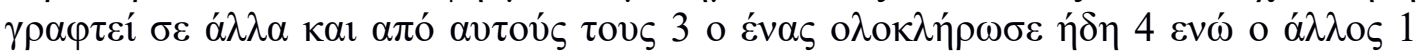

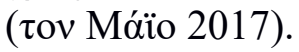

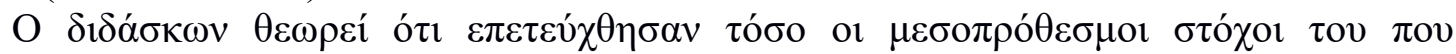

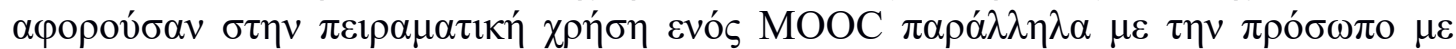

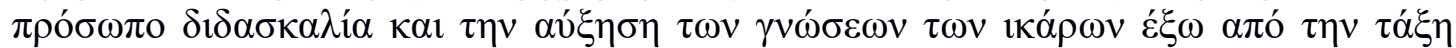

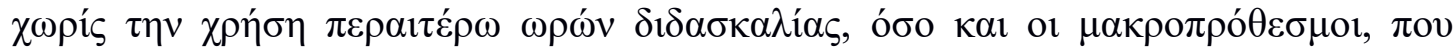

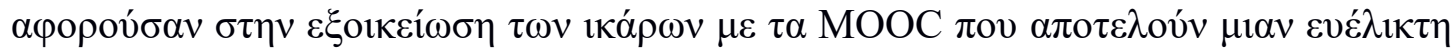

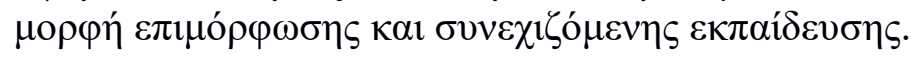

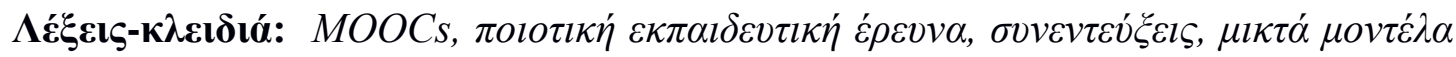
$\mu \alpha \dot{\theta} \eta \sigma \eta \varsigma, \tau \varepsilon \chi v o \lambda o \gamma i ́ \varepsilon \varsigma \Delta \imath \alpha \delta \imath \kappa \tau \dot{o v}, \sigma \tau o i \beta \alpha L A M P$.

\section{Introduction - Literature review}

Since their appearance, MOOCs (Massive Open Online Courses) started affecting and changing education. Although this transformation is still at the beginning (since the MOOCs and the supportive technologies are still evolving), and there are many open research problems about MOOCs (Andreatos, 2015), important changes in all grades of education due to MOOCs are already evident, from elementary school (Cairneagle Associates, 2014) to high school (Jackson, 2013; Brahimi and Sarirete, 2015; Najafi, Evans and Federico, 2014), to higher education (Salisbury, 2014) and even to 
Distance Education (Adham and Lundqvist, 2015), continuing education and intraorganisational learning (Andreatos, 2011; Andreatos, 2015).

According to Brahimi and Sarirete (2015), MOOC penetration in traditional face-toface settings is due to the fact that:

With MOOCs, the teaching method is moving from the traditional transfer

learning model where the teacher serves as the repository and transmitter

of knowledge to the flipped classroom model where the learner interacts

with other students, peers, and has flexible access to all information and

resources around him before coming to the classroom. With the huge

amount of online educational material this has become a useful and

beneficial method in teaching.

Today there are a lot of MOOCs providers all over the world (Andreatos, 2015; Brahimi and Sarirete, 2015; Robertson and Tasso, 2015), many of which offer courses for free. Some providers combine courses and add a capstone project in order to offer specialisations. In general, MOOC cost is reasonable and much lower to that of higher education in the Western world (Andreatos, 2015).

Due to the need for lifelong learning, MOOCs are very attractive to educators, since they form a flexible and economic way of personal development (Andreatos, 2015) advancing the personal Zone of Proximal Development (ZPD; Vygotsky, 1978).

Many surveys have shown that faculty members are not rejecting technology. In fact, most academics believe that technology can support education but at the same time they fear that technological or even commercial considerations, (rather than pedagogical considerations) are driving the phenomenon of MOOCs (Brahimi and Sarirete, 2015; Robertson and Tasso, 2015).

\section{The instructor turns to MOOCs for supplemental student education}

The effort described was implemented in the academic year 2016-2017, in the 5th (Fall) semester, during the Internet Programming course. This course combines a series of technologies including HTML, CSS, HTTP, PHP, phpMyAdmin and the Apache web server. A prerequisite course is Data Bases (using MySQL) taught in the previous (4th) semester, as well as, fluency with the Linux operating system and bash commands. The whole course is taught using open-source technologies - especially the so called LAMP stack.

The goal of the course is to teach students how to build simple web applications consisting of HTML forms in the front-end and PHP scripts querying a MySQL database in the back-end, powered by an Apache web server, all running on a Linux platform.

It is obvious that the 45 didactic hours do not suffice for covering all the aforementioned subjects in depth; therefore, a compromise had to be made: teach only the basics of HTML, CSS, HTTP; recall the basics of the 4th semester's Databases (using MySQL) course, and teach the mechanism of HTML forms, PHP scripts and queries to the MySQL Data Base.

This didactic scenario was sufficient some years ago; however, HTML and CSS have evolved considerably since then, and they could be the subject of a separate course. Therefore the instructor followed this approach: he referred students wishing to learn more HTML to a MOOC provider (Udemy). He selected two free introductory courses on HTML5 and CSS3 from a major MOOC provider and presented them in the class. The students chose one of the two. The instructor attended the course simultaneously with the students (instructor as student). The MOOC attendance was optional, because the instructor knew from his experience that the students would 
object to extra coursework; however, the instructor would give an extra $10 \%$ bonus to the oral grade of the students finishing the course by demonstrating the relevant certificate before the final exam (end of January 2017).

Another reason calling for this option was the acquaintance of the Hellenic Air Force Academy (abbreviated as HAFA) students with continuing education. An early introduction to MOOCs would familiarise students with MOOCs so that they would have alternative educational resources when needed in their carrier.

\subsection{Demographic information}

The population of this educational research were eight out of nine students of the class, one female and seven males, junior students of the $5^{\text {th }}$ semester of HAFA, about 20 years old.

\subsection{Expected students benefits}

The instructor, in order to motivate the students to attend the course, presented the scenario and discussed it with the students; then he presented the following benefits for those who would decide to attend and finish the course:

1) Knowledge of HTML5 and CSS3;

2) Experience with a new way of learning;

3) Certificate; MOOC certificates are mentioned in CV's;

4) Ten percent bonus in the oral grade.

In addition, the instructor would also attend the course and would operate as his students (instructor as student), because HAFA students tend to turn to their fellow students for help.

\subsection{About the MOOC}

The proposed MOOC contains 36 Lectures in Video clips totalling 5 hours. It is offered in English. The required Skill Level is Beginner Level. At that time (October 2016) it had 5,391 students enrolled and it was assessed by 4.5 out of 5 stars by 369 students. At the time this text was typed (Sept. 2017) the course had 22,502 students enrolled and it is still rated 4.5. This grade is relatively high given that the average course has 4.18 stars, fact which guarantees learner satisfaction and minimises dropout (Coursetalk, 2015).

The course covers the topics shown in Fig. 1. 


\begin{tabular}{|lll|}
\hline+ Course Intro & 1 Lecture & $04: 06$ \\
\hline+ Basic HTML & 7 Lectures & $01: 08: 22$ \\
\hline+ CSS Basics & 6 Lectures & $49: 04$ \\
\hline+ Links & 5 Lectures & $29: 18$ \\
\hline+ Layout & 4 Lectures & $48: 40$ \\
\hline+ Tables & 3 Lectures & $23: 55$ \\
\hline+ Forms & 5 Lectures & $44: 49$ \\
\hline+ Video & 3 Lectures & $19: 59$ \\
\hline+ Wrap up & 2 Lectures & $05: 41$ \\
\hline+ Bonus Material & 1 Lecture & $01: 04$ \\
\hline
\end{tabular}

Fig. 1. MOOC sections

The MOOC syllabus can be found on line (https://www.udemy.com/html5fundamentals-for-beginners).

The MOOC plan was clever: the MOOC teacher is building a complete website stepby-step using HTML5 and CSS3 in eight sections. He starts from a very simple site and he introduces new concepts in each section, which then he uses in the course project in order to advance it.

\section{Diary/ Schedule}

The instructor introduced two courses for the students to choose at the beginning of October 2016. During the class of the 5th of October 2016, after a brief discussion, the students chose one of the proposed courses and agreed to start attending the videos as soon as possible. The instructor used a researcher's diary to note the students' progress.

From time to time the instructor was asking the students about their progress as well as their opinion about the course and was recording notes in his diary. It was noticed that the students' progress was varying greatly at the beginning. However, the progress of the most eager (active) students acted as a motivation for the rest, so that they were not left behind, with the exception of one student who refused to participate due to lack of interest. As expected, his performance was low in the course also. Fig. 2 shows the research plan. 


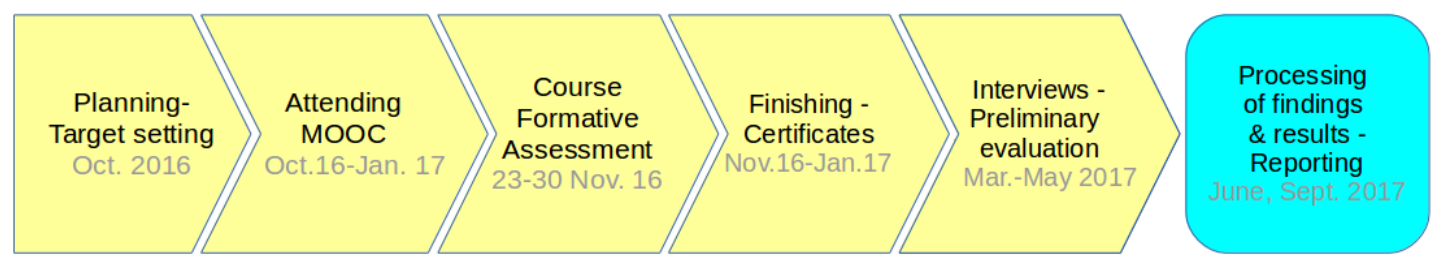

Fig. 2. The research plan

The instructor finally finished the course by October 25, 2016, because he was familiar with the course material, as well as, a frequent MOOC learner (Andreatos, 2011). Then he demonstrated his certificate to the class (Fig. 3) in order to motivate the students.

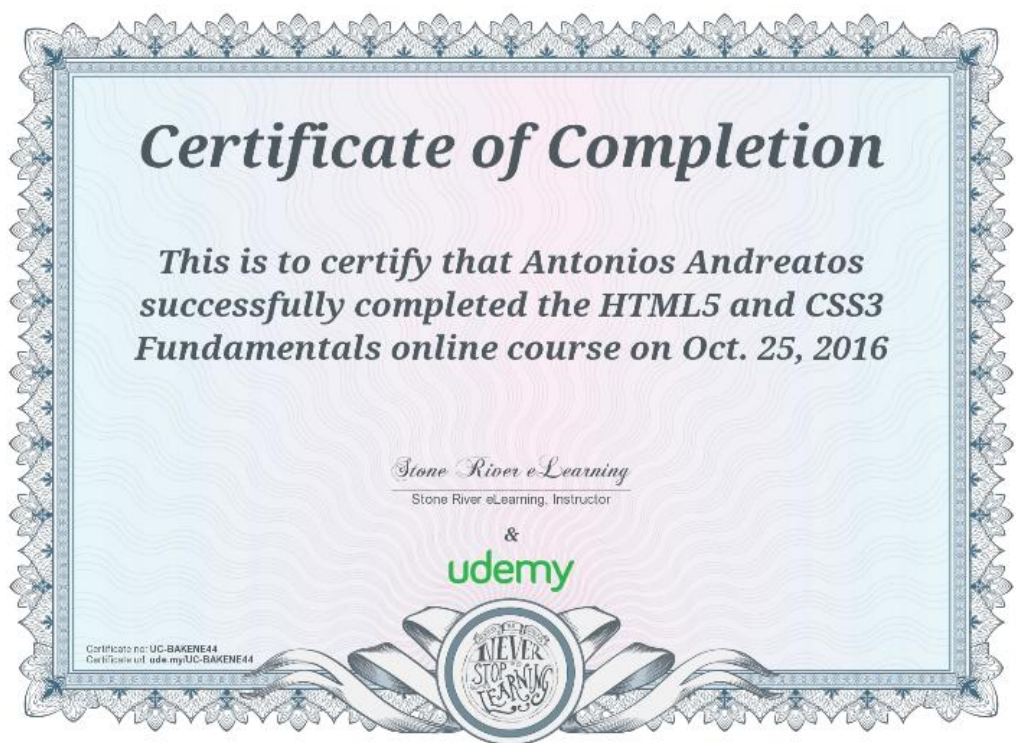

Fig. 3. The MOOC certificate

It was observed that the students did not ask questions about the MOOC content, which implies that the material was presented well and high quality.

\section{Assessing the experiment}

Two months after the course (and after the exams of the fall semester) the instructor interviewed all eight students. From these interviews some interesting results emerged that will be presented in the next subsection.

\subsection{Research results}

In general, the following conclusions may me drawn from the interviews:

- For all of the students this was their first contact with the MOOCs;

- Their first impressions were positive;

- They liked this way of learning;

- In general, the students were satisfied with the MOOC teacher because they were able to easily follow him and to understand the concepts presented in the videos. One of the students added that the MOOC instructor delivers the course clearly; another student added that if he has not understood something well, he turns the video back. It seems that they did not use the MOOC forum to pose questions;

- Out of eight students, six presented a certificate while the other two reached close to the end (missing 1 and 3 lectures respectively); 
- One of the students who did not finish the MOOC declared that he was attending the lectures only during the weekends. This student faced the following problem: he could not recall the previous lectures, and so he had to repeat them before going on;

- The other student who did not finish the course considers MOOCs inferior to faceto-face teaching because he cannot ask questions to the teacher and get immediate answers;

- One of the students declared that he would willingly take MOOCs in parallel with his face-to-face courses in the future if the syllabus were comparable;

- Six out of the eight students subscribed to additional MOOCs of their interest.

One of the students was so excited with the MOOC learning method that he immediately subscribed to four other courses from Udemy! One of these courses was related to background material offered by HAFA during the second year of studies and the other three were related to courses offered by HAFA during the fourth year of studies! He finished these four courses before the HTML5 and CSS3 MOOC and after that, he subscribed to another 3-4 MOOCs to attend during the Easter holidays (April 2017).

\section{Discussion and Conclusion}

The educational experiment presented here shows that the students assessed positively their first MOOC experience independently of the face-to-face course assessment (which was average).

In general, the students were satisfied with the MOOC teacher because they were able to comprehend him and understand the concepts presented in the videos. It was critical for the students to be able to easily follow a MOOC instructor in order to successfully finish the course; this is fairly reasonable, taking into account that the courses are given in English which is not their native tongue.

The relatively high success rate (six out of eight students or $75 \%$ ), compared to 4-8\% which is the average in MOOCs (Andreatos, 2015) is due to the high motivation and support by the instructor and fellow students, as well as, the fact that the students are already active in the learning process, compared to adult learners who have graduated some years ago.

The instructor's short-term goals were related to the HAFA course; The instructor's long-term goals were the use of MOOCs in parallel with face-to-face courses and even further, the introduction to lifelong learning via MOOCs (Andreatos, 2015). Judging by the results, the instructor feels that both the short-term as well as the longterm goals were met, to a different degree, depending on the students' willingness and initiative.

\section{References}

Adham, R. S. and Lundqvist, K. O. (2015). MOOCs as a Method of Distance Education in the Arab World - A Review Paper. Retrieved 3 Sept. 2017 from: http://www.eurodl.org/materials/contrib/2015/ Adham_Lundqvist.pdf.

Andreatos, A. (2011). The use of open educational resources in intra-organisational e-learning and continuing education. Proceedings of the 10th European Conference on e-Learning - ECEL 2011, University of Brighton, Brighton, UK. 10-11 November 2011.

Andreatos, A. (2015). The Use of MOOCs in the Continuing Education of Individuals and Organisations, in Anabela Mesquita and Paula Peres (Eds), Furthering Higher Education Possibilities through Massive Open Online Courses, IGI Global: http://www.igiglobal.com/publish/call-for-papers/ call-details/1190.

Brahimi, T. and Sarirete, A. (2015). Learning outside the classroom through MOOCs. Computers in Human Behavior, 51, 604-609. https://doi.org/10.1016/j.chb.2015.03.013. 
Cairneagle Associates (2014). MOOCs: Opportunities for their use in compulsory-age education. Retrieved 3 Sept. 2017 from: https://goo.gl/9VAd6s.

Coursetalk (2015). What Reviews Divulge About Online Education. Retrieved 3 Sept. 2017 from: https://d3q6qq2zt8nhwv.cloudfront.net/s/coursetalk/pdf/newco/What\%20Reviews\%20Divulge $\% 20$ About\%20Online\%20Education.0b7d48034dcd.pdf.

Jackson, M. N. (2013). MOOCs go to K12: Higher ed trend expands to high schools. District Administration. Retrieved 3 Sept. 2017 from: http://goo.gl/xtjJhc.

Kolowich, S. (2013). American Council on Education recommends 5 MOOCs for college credit, The Chronicle of Higher Education. Retrieved 3 Sept. 2017 from: http://chronicle.com/article/American-Council-on-Education/137155.

Najafi, H., Evans, R. and Federico, C. (2014). MOOC Integration into Secondary School Courses. The International Review of Research in Open and Distributed Learning, 15(5), 306-322. Retrieved 3 Sept. 2017 from: http://www.irrodl.org/index.php/irrodl/article/view/1861/3098.

Robertson, R. W. and Tasso, C. (2015). MOOCs: global education paradigm shift? Revista Tecnología, Ciencia y Educación, no. 1, May-Aug. 2015, pp. 39-45.

Salisbury, A. D. (2014). Impacts of MOOCs on Higher Education. Retrieved 3 Sept. 2017 from: https://www.insidehighered.com/blogs/higher-ed-beta/impacts-moocs-higher-education.

Vygotsky, L. S. (1978). Mind in society: The development of higher psychological processes. Cambridge, MA: Harvard University Press. 